\title{
Deleted in Colorectal Cancer (DCC) Regulates the Migration of Luteinizing Hormone-Releasing Hormone Neurons to the Basal Forebrain
}

\author{
Gerald A. Schwarting,, ${ }^{1,2}$ Christine Kostek, ${ }^{1}$ Elizabeth P. Bless, ${ }^{1}$ Naira Ahmad, ${ }^{1}$ and Stuart A. Tobet ${ }^{1,3}$ \\ ${ }^{1}$ The Shriver Center, Waltham, Massachusetts 02452, and Departments of ${ }^{2}$ Cell Biology and ${ }^{3}$ Physiology, University of \\ Massachusetts Medical School, Worcester, Massachusetts 01655
}

\begin{abstract}
Luteinizing hormone-releasing hormone (LHRH) neurons migrate from the vomeronasal organ (VNO) to the forebrain in all mammals studied. In mice, most LHRH neuron migration is dependent on axons that originate in the VNO but bypass the olfactory bulb and project into the basal forebrain. Thus, cues that regulate the trajectories of these vomeronasal axons are candidates for determining the destination of LHRH neurons. Using in situ hybridization techniques, we examined the expression of Deleted in colorectal cancer (DCC), a vertebrate receptor for the guidance molecule netrin-1, during development of the olfactory system. DCC is expressed by cells in the olfactory epithelium (OE) and VNO, and in cells migrating from the OE and VNO from embryonic day 11 (E11) to E14. Some $\mathrm{DCC}^{+}$cells on vomeronasal axons in the nose also express LHRH. However, DCC expression is downregulated beginning
\end{abstract}

Luteinizing hormone-releasing hormone (LHRH) neurons that are thought to regulate pituitary function in mammals arise in the olfactory placode, migrate along the nasal septum, cross the cribriform plate under the developing olfactory bulb, and proceed deep into the developing forebrain (Schwanzel-Fukuda and Pfaff, 1989; Wray et al., 1989; Ronnekleiv and Resko, 1990; Norgren and Brackenbury, 1993; Quanbeck et al., 1997; Skynner et al., 1999). We have previously shown that LHRH neuron migration is axophilic, that is, these neurons migrate in contact with the caudal branch of the vomeronasal nerve (cVNN) (Yoshida et al., 1995). In mice, the cVNN makes a characteristic turn ventrally after reaching the rostral forebrain. LHRH neurons turn and migrate toward the hypothalamus in conjunction with the cVNN. Thus, the destination of LHRH cells is at least in part determined by factors that regulate the trajectories of the cVNN.

Chemoattractants and repulsive molecules can exert their influence on growth cones as regulators of axon guidance and on cell soma as determinants of cell migration. Netrins are particularly versatile guidance molecules. Netrin-1 attracts commissural axons in chick spinal cord (Kennedy et al., 1994; Serafini et al., 1994) but repels trochlear motor axons (Colamarino and TessierLavigne, 1995). Unc-6, the Caenorhabditis elegans homolog of

Received July 25, 2000; revised Oct. 16, 2000; accepted Nov. 2, 2000.

This work was supported by National Institutes of Health Grants HD33441 and DC00953. We thank Marc Tessier-Lavigne for heterozygote DCC mutant mice. We also thank Laurent Pays for help with the figures and Denise Brescia for proofreading this manuscript.

Correspondence should be addressed to Gerald A. Schwarting, The Shriver Center, 200 Trapelo Road, Waltham, MA 02452. E-mail: GSchwarting@Shriver.org. Copyright (C) 2001 Society for Neuroscience 0270-6474/01/210911-09\$15.00/0 at E12, so few if any LHRH neurons in the forebrain also express DCC. In rat, DCC is expressed on TAG- $1^{+}$axons that guide migrating $\mathrm{LHRH}$ neurons. We therefore examined $\mathrm{LHRH}$ neuron migration in $\mathrm{DCC}^{-1-}$ mice and found that trajectories of the caudal vomeronasal nerve and positions of LHRH neurons are abnormal. Fewer than the normal number of LHRH neurons are found in the basal forebrain, and many LHRH neurons are displaced into the cerebral cortex of $\mathrm{DCC}^{-1-}$ mice. These results are consistent with the idea that DCC regulates the trajectories of a subset of vomeronasal axons that guide the migration of LHRH neurons. Loss of DCC function results in the migration of many LHRH neurons to inappropriate destinations.

Key words: DCC; luteinizing hormone-releasing hormone; axon guidance; cell migration; vomeronasal; olfactory

netrin-1, also mediates attractive and repulsive responses for different axon populations (Hedgecock et al., 1990). In the developing mouse cerebellum, netrin-1 expression may establish a repulsive zone that is avoided by migrating granule cell precursors (Ackerman et al., 1997; Przyborski et al., 1998). Two mammalian netrin-1 receptors have been identified: Deleted in colorectal cancer (DCC), a transmembrane protein belonging to the Ig superfamily (Keino-Masu et al., 1996), and Unc5h3, the mouse homolog of C. elegans Unc-5 (Leonardo et al., 1997). In mice deficient in DCC, the corpus callosum and anterior commissure are missing or diminished in size (Fazeli et al., 1997), and in Unc5h3 mutant mice, the cerebellum is reduced in size and exhibits abnormal foliation (Przyborski et al., 1998). In the olfactory system, DCC protein is heavily expressed in mitral cell axons of the olfactory bulb as early as E14 in the rat, but declines in intensity by E18 in the lateral olfactory tract (Shu et al., 2000). DCC mRNA expression has also been detected in the rat olfactory epithelium and in ensheathing cell precursors (Livesey and Hunt, 1997). Deiner and Sretavan (1999) recently demonstrated the presence of netrin-1 in the hypothalamus and median eminence (ME) and suggested that netrin and DCC interactions could play a role in LHRH neuron migration and in axon pathfinding by LHRH axons.

We show here that DCC is expressed primarily in cells in the vomeronasal organ (VNO) and along the vomeronasal nerve $(\mathrm{VNN})$ and by their axons that project directly into the forebrain. DCC mRNA is also expressed on a subset of LHRH neurons in the nose but diminishes before these neurons cross the cribriform plate into the forebrain. Furthermore, we show that the forebrain- 
projecting axons are misguided in DCC-deficient mice, resulting in the migration of LHRH neurons to inappropriate destinations.

\section{MATERIALS AND METHODS}

Animals and tissue. Timed-pregnant rats were purchased from Zivic Miller (Portersville, PA), and C57BL/6 mice were obtained from a breeding colony maintained at the Shriver Center. DCC-deficient mice were provided by Dr. Marc Tessier-Lavigne (University of California, San Francisco, CA). These mice were originally generated on a $129 / \mathrm{Sv}$ background (Fazeli et al., 1997) but were mated onto a CD-1 background (Deiner and Sretavan, 1999). Embryonic day 11 (E11)-E17 embryos (plug day, 0) were harvested from anesthetized timed pregnant mice. DCC-deficient mice were obtained from heterozygote matings and were identified by genotyping the DCC embryos (Fazeli et al., 1997).

Animals were deeply anesthetized with a mixture of ketamine (50 $\mathrm{mg} / \mathrm{kg}$, body weight) and xylazine $(10 \mathrm{mg} / \mathrm{kg}$, body weight $)$, and individual embryos or postnatal pups were perfused transcardially using $4 \%$ paraformaldehyde in $0.1 \mathrm{M}$ phosphate buffer, $\mathrm{pH} 7.4$, or with periodatelysine-paraformaldehyde in $0.05 \mathrm{M}$ phosphate buffer $(2 \%$ paraformaldehyde, $0.075 \mathrm{M} \mathrm{L}$-lysine, and $0.214 \%$ sodium metaperiodate) in accord with the Institutional Animal Care and Use Committee at the Shriver Center. The heads were post-fixed overnight and then cryopreserved in PBS containing $30 \%$ sucrose, $\mathrm{pH} 7.4$, at $4^{\circ} \mathrm{C}$.

In situ hybridization. A 575 base pair DCC cDNA sequence was generated from E15 mouse brain tissue by RT-PCR with the First-Strand cDNA Synthesis Kit (Clontech, Palo Alto, CA) and cloned using the TOPO-TA cloning kit (Invitrogen, Carlsbad, CA) with the following primers: 5'-CCC AGT CCA AGG TTA CAG ATT-3' and 5'-GAG GTG TCC AAC TCA TGA TG-3' (Cooper et al., 1995). A 550 base pair netrin-1 cDNA sequence was generated in the same manner from postnatal day $0(\mathrm{P} 0)$ mouse hindbrain tissue using the following primers: 5'-CGA GAC GAC AGT CTG GTG TGT GAC T-3' and 5'-CCT TTG GWG GCC TTG CAA TAG GAA T-3'. DIG-labeled RNA probes were generated according to the methods described in the Boehringer Mannheim Genius kit (Roche, Indianapolis, IN). In situ hybridization was performed on $20-\mu \mathrm{m}$-thick coronal cryostat sections through the olfactory epithelium $(\mathrm{OE})$ and olfactory bulb $(\mathrm{OB})$ of mice. Briefly, slides were treated with proteinase $\mathrm{K}$ (Roche), exposed to acetic anhydride in $0.1 \mathrm{M}$ triethanolamine for $10 \mathrm{~min}$, and then dehydrated through graded ethanol solutions. Hybridization was performed at $55-56^{\circ} \mathrm{C}$ for $15 \mathrm{hr}$. Slides were washed in $\mathrm{SSC}$ at $55^{\circ} \mathrm{C}$ followed by a formamide wash at $55^{\circ} \mathrm{C}$ and SSC washes at $37^{\circ} \mathrm{C}$. DIG-labeled RNA hybrids were reacted with alkaline phosphatase-conjugated anti-DIG Fab antibodies (Roche). Reaction product was visualized by incubating the sections with nitroblue tetrazolium chloride and 5-bromo-4-chloro-3-indolylphosphate (Sigma, St. Louis, MO) at room temperature for $15 \mathrm{hr}$.

Antibodies. For the immunohistochemical analyses, LHRH neurons were labeled using the LR1 anti-LHRH antibody $(1 / 10,000)$, a generous gift from Dr. Robert Benoit (Montreal General Hospital Research Institute, Montreal, Canada). For the investigation concerning the TAG-1 adhesion molecule, the 4D7 monoclonal antibody (1/1) was used (Yamamoto et al., 1986). Mouse monoclonal anti-DCC antibody (1/2500) was obtained from Oncogene Research (Cambridge, MA), and anti-peripherin antibody (1/5000) was obtained from Chemicon (Temecula, CA)

Immunocytochemistry and immunofluorescence. For immunocytochemical experiments, heads from DCC mutant, heterozygote, and wild-type mouse embryos and newborns were embedded in 5\% agarose and cut sagittally at $60 \mu \mathrm{m}$ with a vibrating microtome or were rapidly frozen and sectioned at $40 \mu \mathrm{m}$ with a sliding microtome. Sections were placed in containers with nytex mesh bottoms $0.05 \mathrm{M}$ PBS, pH 7.4, and were pretreated at $4^{\circ} \mathrm{C}$ as follows: $0.1 \mathrm{M}$ glycine in PBS for $30 \mathrm{~min}, 0.5 \%$ sodium borohydride in PBS for $15 \mathrm{~min}$, and 5\% normal goat serum (NGS) with $0.3 \%$ Triton X-100 (Tx)-PBS and 1\% hydrogen peroxide for $30 \mathrm{~min}$. Sections were then incubated in antibodies to LHRH or peripherin in $1 \%$ BSA with $0.3 \% \mathrm{Tx}$ for two nights at $4^{\circ} \mathrm{C}$. Tissue sections were then washed for $1 \mathrm{hr}$ in $1 \%$ NGS with $0.02 \%$ Tx and incubated with the appropriate biotinylated secondary antibodies (Jackson ImmunoResearch, West Grove, PA) at 1:250 dilution in 1\% NGS with $0.32 \%$ Tx for $2 \mathrm{hr}$ at room temperature. After washes in $0.02 \% \mathrm{Tx}-\mathrm{PBS}$, sections were incubated in $\mathrm{ABC}$ reagent (Vector Laboratories, Burlingame, $\mathrm{CA}$ ) for 1 $\mathrm{hr}$, washed for $1 \mathrm{hr}$ in Tris-buffered saline (TBS), and developed with $0.025 \% 3,3^{\prime}$-diaminobenzidine in TBS with $0.2 \%$ nickel ammonium and $0.02 \%$ hydrogen peroxide. Sections were then washed in TBS and mounted on slides with Permount (Fisher Scientific, Springfield, NJ).
For immunofluorescence experiments, $70 \mu \mathrm{m}$ sections were incubated overnight at $4^{\circ} \mathrm{C}$ with primary antibody diluted in PBS containing $1 \%$ BSA and $0.02 \%$ Tx. FITC- and Cy3-conjugated secondary antibodies (Jackson ImmunoResearch) were diluted in PBS containing 1\% BSA and incubated with the sections for $2 \mathrm{hr}$ at room temperature.

Combined fluorescence in situ hybridization and immunocytochemistry. For cryosection experiments in mice, we used a protocol for fluorescence double-labeling by in situ hybridization and immunocytochemistry (Wanner et al., 1997). The DCC digoxigenin-riboprobe was detected using a Tyramide Signal Amplification-Direct Cy3 kit (NEN). LHRH cells were visualized using the LR1 antibody and FITC-conjugated donkey anti-rabbit IgG (Jackson ImmunoResearch). Minor adaptations were made concerning the hybridization buffer, which contained $10 \mathrm{~mm}$ Tris-HCl, pH 7.5, $300 \mathrm{~mm} \mathrm{NaCl,} 1$ mm EDTA, 50\% deionized formamide, $10 \%$ dextran sulfate, and $1 \%$ blocking reagent (Roche).

Data analysis. $\mathrm{LHRH}^{+}$cells were counted from DCC ${ }^{+/+}(\mathrm{E} 13, n=4$; $\mathrm{E} 15, n=4 ; \mathrm{P} 0, n=3), \mathrm{DCC}^{+-}(\mathrm{E} 13, n=3 ; \mathrm{E} 15, n=3 ; \mathrm{P} 0, n=3)$ and $\mathrm{DCC}^{-1-}(\mathrm{E} 13, n=3 ; \mathrm{E} 15, n=5 ; \mathrm{P} 0, n=3)$ in three main compartments (nasal compartment, dorsal forebrain, and ventral forebrain) using an Axioplan microscope (Zeiss, Thornwood, NY) at $400 \times$ magnification. Cells containing a dense accumulation of immunoreactive LHRH were counted if they had standard size (10-15 $\mu \mathrm{m}$ diameter) and fusiform morphology. Counts were taken from either alternating sections or from serial sections. Because alternating sections provided counts equivalent to half the total number, estimates for the total number of $\mathrm{LHRH}^{+}$cells were used for analyses. The boundary between the nasal compartment and the dorsal forebrain was defined by the cribriform plate. The boundary between the dorsal and ventral forebrain was created by drawing a line from the caudalmost tip of the cortex, following the ventral surface of the cortex to the rhinencephalic sulcus at the base of the olfactory bulb (see Fig. 6). An area within the dorsal forebrain indicative of more extreme mistargeting was also analyzed. This area was designated cortex (see Fig. 6) and included all $\mathrm{LHRH}^{+}$cells in the dorsal forebrain not located within the olfactory bulb or ventral to the olfactory bulb. Data were analyzed with the JMP3.2.2 computer program (SAS Institute, Cary, NC). A one-way ANOVA was used for each measure (genotype) at each age, and when a significant difference was found, post hoc comparisons using Tukey-Kramer were performed.

\section{RESULTS}

\section{DCC mRNA expression in the mouse olfactory system}

A riboprobe specific for the fibronectin repeat region of the mouse DCC gene was made as previously described (Cooper et al., 1995). Using in situ hybridization techniques, DCC mRNA was expressed by several cell types in the early stages of olfactory development. At E11, the olfactory placode has differentiated into a distinct $\mathrm{OE}$ and $\mathrm{VNO}$, although the $\mathrm{VNO}$ is still in the process of budding off the medial wall of the OE (Halpern, 1987; Garrosa et al., 1992). $\mathrm{DCC}^{+}$cells were located in the VNO and $\mathrm{OE}$ at this age (Fig. $1 A$ ). There were also $\mathrm{DCC}^{+}$cells that had migrated from the VNO toward the forebrain, as well as $\mathrm{DCC}^{+}$ cells in the migrating mass (MM) (DeCarlos et al., 1995) that had migrated from the OE. One day later, at E12 (Fig. 1B), cells in all four locations still expressed DCC message, but the levels of expression had begun to decline. The level of DCC mRNA expression in cells of the olfactory compartment was very low compared with expression in the forebrain at these ages. DCC mRNA expression declined rapidly from E13 to E15, first in the $\mathrm{OE}$, then in the VNO (data not shown). At E15, no DCC mRNA expression was detected in the peripheral olfactory system (Fig. $1 C)$. A control sense probe showed no specific hybridization with mouse tissue (data not shown).

We also examined the pattern of expression of netrin-1 mRNA to determine its relationship to the positions of cells expressing DCC mRNA. In a sagittal section through an E12 mouse nose and forebrain, netrin-1 mRNA was heavily expressed in the proliferating neuroepithelium of the ventral forebrain at the rostral tip of the third ventricle (Fig. $2 A$, open arrowhead). This is a 

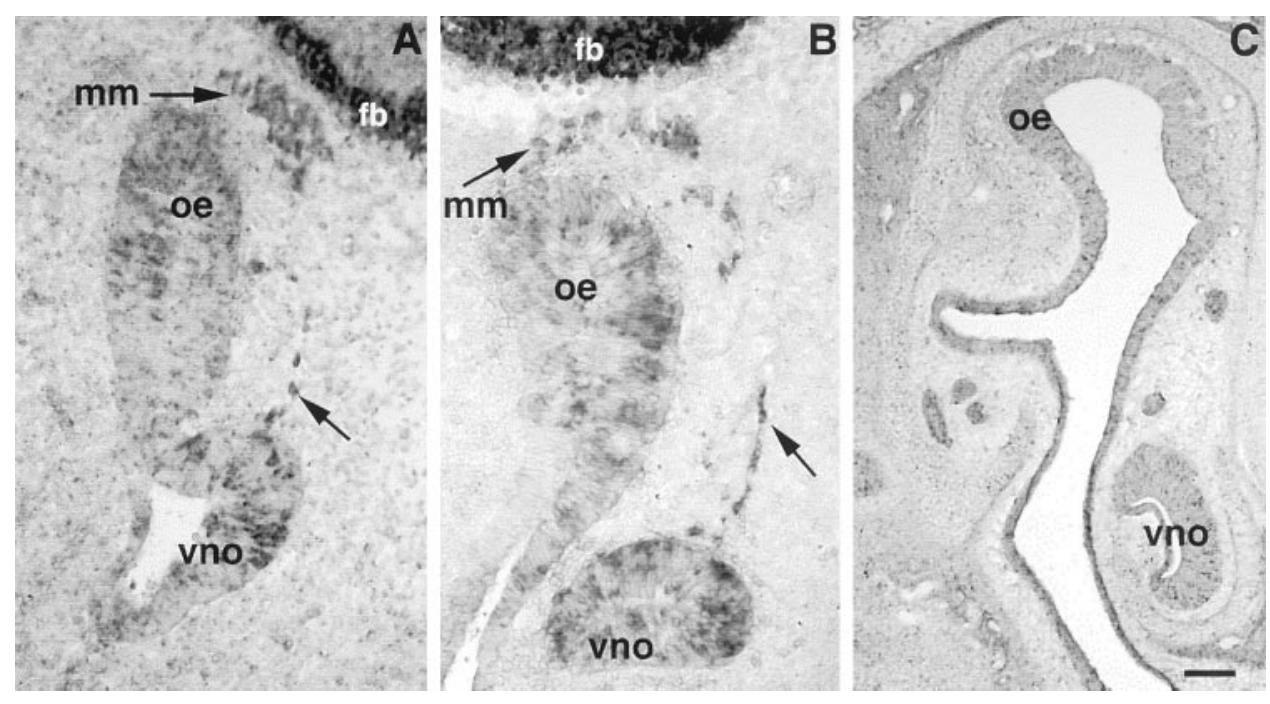

Figure 1. DCC is expressed in the mouse embryonic olfactory system. At E11 $(A)$ and $\mathrm{E} 12(B)$, in coronal sections in situ hybridization reveals DCC expression in groups of cells in the olfactory epithelium (oe) and developing vomeronasal organ (vno). There are also cells that have migrated away from the VNO (arrows) and cells in the migrating mass $(\mathrm{mm})$ that have migrated from the OE. Cells in the forebrain $(f b)$ and developing olfactory bulb also express DCC. At E15 $(C)$, DCC is no longer expressed by cells in the OE, VNO, or by migrating cells. Medial is left, dorsal is up. Scale bar: $A, B, 50 \mu \mathrm{m} ; \mathrm{C}, 100 \mu \mathrm{m}$.

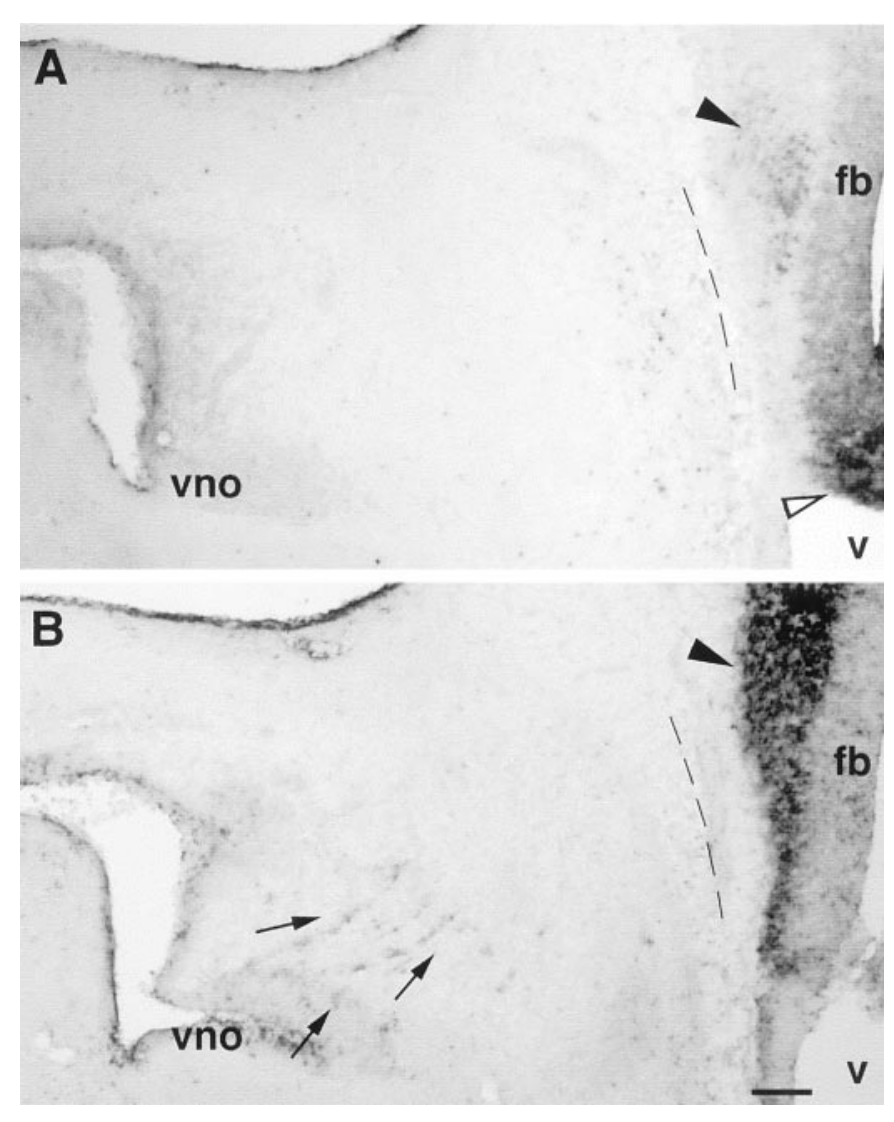

Figure 2. Expression of netrin-1 and DCC in mouse nose and forebrain. In the E12 forebrain, netrin- $1^{+}$and $\mathrm{DCC}^{+}$cells are largely expressed in a complementary pattern. Netrin- 1 is heavily expressed $(A$, open arrow$h e a d)$ in the ventricular and subventricular zones of the forebrain $(f b)$, particularly at the rostral tip of the third ventricle $(v)$ that will become the region of the OVLT. Netrin-1 expression rapidly decreases in more dorsal regions of the developing forebrain. In contrast, DCC $(B)$ is expressed in postmitotic zones throughout the telencephalon $(B$, arrowhead) and only overlaps with netrin- $1^{+}$in a region that will become the diagonal band of Broca. DCC is also expressed in cells in the VNO and on vomeronasal axons extending from the VNO ( $B$, arrows). The position of the cribriform plate is shown as a dashed line. Dorsal is up, rostral is left. Scale bar, $100 \mu \mathrm{m}$. region that will become the region of the organum vasculosum of the lamina terminalis (OVLT), a location that is a major destination for $\mathrm{LHRH}^{+}$fibers and a region around which many LHRH neurons will finally reside. Netrin-1 expression decreased abruptly in more dorsal regions of the neuroepithelium. There was also significant netrin-1 expression more rostrally in the basal telencephalic regions that differentiate into the diagonal bands of Broca (Fig. 2A, arrowhead) and this is also a significant site for LHRH neuron migration and destination for a subset of the final population. In an adjacent section to Figure $2 A$, DCC mRNA was expressed in postmitotic zones of the rostral telencephalon (Fig. $2 B)$. Except for the cluster of netrin $-1^{+}$cells in the presumptive diagonal band region, DCC expression was complementary to the pattern of netrin-1 expression in the rostral forebrain. Finally, as shown in the previous figure, $\mathrm{DCC}^{+}$cells were also present in the $\mathrm{VNO}$ and on axons extending from the VNO toward the forebrain (Fig. 2B).

\section{DCC protein expression in the rat olfactory system}

An antibody to DCC made in mice recognized rat DCC, but not mouse DCC in immunocytochemical experiments. Double-label immunofluorescence studies were performed on horizontal sections of E14 and E16 rat nose and forebrain to determine the location of DCC protein. The tissue was double-labeled with antibodies to TAG-1, another Ig superfamily member (Dodd et al., 1988) that is specifically expressed by vomeronasal nerves in the nose $(\mathrm{nVNN})$ and the caudal branch of the vomeronasal nerve (cVNN) (Yoshida et al., 1995). DCC and TAG-1 immunoreactivities were very similar. Their expression overlapped on the $\mathrm{nVNN}$ as it emerged from the VNO (Fig. $3 A-C$ ) and they were coexpressed on the $\mathrm{cVNN}$ at E16 after it crossed the cribriform plate and extended along the medial surface of the olfactory bulb and forebrain (Fig. $3 D-F$ ). We were unable to detect any cell soma that was clearly DCC immunoreactive. However, combined analysis by in situ hybridization and immunocytochemistry strongly suggested that $\mathrm{DCC}^{+}$fibers in the $\mathrm{VNN}$ originate from $\mathrm{DCC}^{+}$cells of vomeronasal origin.

\section{Expression of DCC in subsets of LHRH neurons}

LHRH neurons begin to migrate from the VNO at the same time and along the same route as $\mathrm{DCC}^{+}$cells shown in Figure 1. To determine whether the same population of cells in mice expressed these two molecules, we performed double-label in situ hybrid- 
Figure 3. DCC is expressed on TAG- $1^{+}$vomeronasal axons in rat. At the top left is a schematic drawing of a horizontal section through the embryonic nose and forebrain. The blue box depicts a region of the $\mathrm{VNO}$ and $\mathrm{OE}$ shown in $A-C$. The red box outlines a region of the forebrain shown in $D-F$. In double-label immunofluorescence studies of horizontal sections through the nasal compartment of the E14 rat, TAG-1 immunoreactivity is detected on the nasal vomeronasal nerve $(A, a r$ rows), which originates in the vomeronasal organ and extends between the septum and the olfactory epithelium $(o e)$. DCC is also expressed on the vomeronasal nerve $(B$, arrows). A double-label image reveals that most vomeronasal nerve fibers express both molecules $(C)$. In a confocal image of a horizontal section at E16, TAG-1 $(D)$ and DCC $(E)$ are both expressed by caudal vomeronasal (arrows) axons growing past the forebrain $(f b)$. Medial is right, caudal is up. DCC is expressed by a subset of LHRH cells. In sagittal sections through the nose and forebrain of an E12 mouse, fluorescence in situ hybridization reveals five distinct $\mathrm{DCC}^{+}$cells along the vomeronasal nerve in the nasal compartment $(G, a r$ rowheads). Fluorescence immunocytochemistry for LHRH on the same section as in $G$, reveals four $\mathrm{LHRH}^{+}$ neurons $(H$, arrows $)$. In a double-label image ( $I$ ) showing both DCC and LHRH fluorescence, two cells (arrows and arrowheads) are $\mathrm{DCC}^{+} / \mathrm{LHRH}^{+}$, three cells are $\mathrm{DCC}^{+} / \mathrm{LHRH}^{-}$, and two cells are DCC-/ $\mathrm{LHRH}^{+}$. The cribriform plate is to the top left, and the $\mathrm{VNO}$ is to the bottom right. Scale bar: $A-C, 50 \mu \mathrm{m} ; D-F, 25 \mu \mathrm{m} ; G-I, 10 \mu \mathrm{m}$.
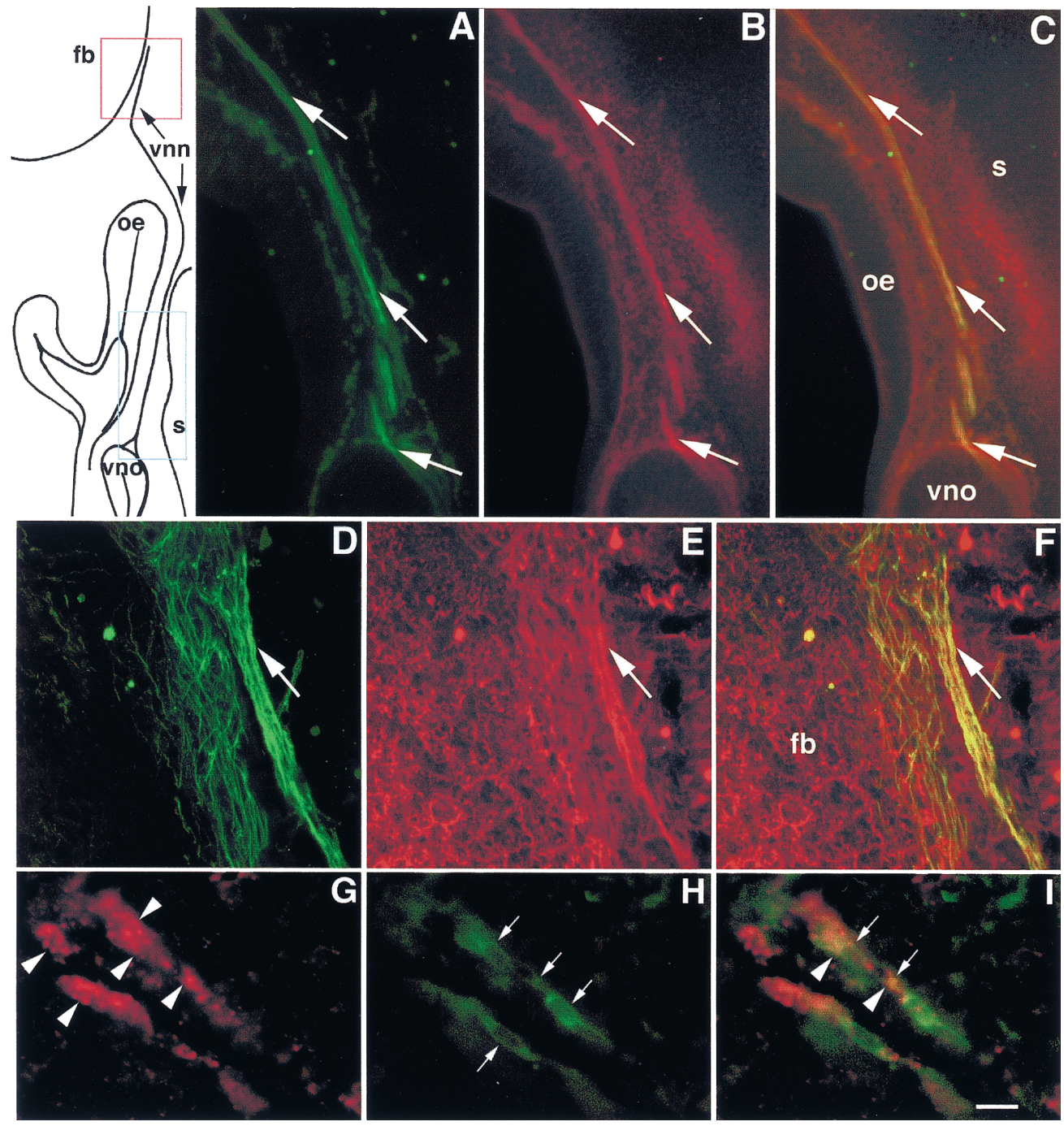

ization studies for DCC and immunofluorescence for LHRH. In a sagittal section through the nasal compartment adjacent to the VNO of an E12 mouse, DCC mRNA was detected in five cells migrating along the nVNN (Fig. $3 G$ ). On the same section, four $\mathrm{LHRH}^{+}$cells were detected by immunofluorescence (Fig. $3 H$ ). The double-label image (Fig. 3I) revealed two cells that were positive for both DCC and LHRH, whereas two cells were single labeled for $\mathrm{LHRH}$, and three cells were $\mathrm{DCC}^{+}$only. At E12, when DCC expression peaked, we detected as many as $600 \mathrm{DCC}^{+}$ cells in the VNO and on the nasal VNN by in situ hybridization. We estimate that $<20 \%$ of these $\mathrm{DCC}^{+}$neurons also expressed LHRH at this age. At all ages, the number of $\mathrm{DCC}^{+}$cells decreased dramatically near the cribriform plate, and few $\mathrm{DCC}^{+}$ cells crossed into the forebrain (data not shown). As mentioned above no cells in positions suggestive of migration were $\mathrm{DCC}^{+}$ after E14.

\section{LHRH neuron numbers in DCC mutant mice}

The total number of LHRH cells in E13 mice did not differ between $\mathrm{DCC}^{+/+}(1104.5 \pm 169.1$, mean $\pm \mathrm{SEM}), \mathrm{DCC}^{+/-}$ $(1245 \pm 35.6)$, and $\mathrm{DCC}^{-/-}(1149.7 \pm 105.0)$. However, there was a significant difference $\left(F_{(2,11)}=4.79 ; p<0.05\right)$ in total number of LHRH-labeled cells in E15 mice, DCC ${ }^{+/+}(1414 \pm$ 168.6), $\mathrm{DCC}^{+/-}(1600 \pm 60.1)$, and $\mathrm{DCC}^{-/-}(1124.4 \pm 57.6)$ that was attributable to the low number of LHRH cells in the mutants.
Although there was not a statistically significant difference in the number of LHRH cells among all three groups, at P0 there was an obvious decrease in the total number of LHRH cells in $\mathrm{DCC}^{-/-}(521 \pm 55.0)$ compared with $\mathrm{DCC}^{+/+}(804 \pm 166.7)$

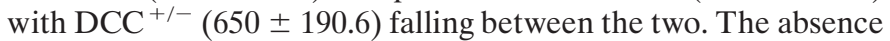
of a statistically significant difference in total number of cells at $\mathrm{P} 0$ is attributable in part to the high variability found in the heterozygotes. The cause of the lower number of LHRH cells in $\mathrm{DCC}^{-1-}$ mice at $\mathrm{E} 15 / \mathrm{P} 0$ is not known, but may relate to their migration to inappropriate destinations, as shown below.

\section{LHRH neuron locations in DCC mutant mice}

Disruption of the DCC receptor gene resulted in fewer LHRH neurons turning ventrally in the forebrain, and therefore more neurons migrated dorsally. There was a significant difference in the percentage of dorsal LHRH cells between genotypes at E13 $\left(F_{(2,9)}=10.59 ; p<0.05\right), \mathrm{E} 15\left(F_{(2,11)}=40.8 ; p<0.05\right)$, and P0 $\left(F_{(2,8)}=11.38 ; p<0.05\right)$. At E13, there was a significantly greater percentage of $\mathrm{LHRH}$ cells located dorsally in $\mathrm{DCC}^{-1-}$ mice as compared with $\mathrm{DCC}^{+/+}$mice $(p<0.05$; Tukey-Kramer HSD). At this age, there was also the suggestion of a gene dosage effect with $\mathrm{DCC}^{+/-}$mice having an intermediate percentage of labeled cells in the dorsal brain that did not significantly differ from that of either $\mathrm{DCC}^{+/+}$or $\mathrm{DCC}^{-/-}$mice (Fig. $4 A$ ). However, at E15 and $\mathrm{P} 0$ the percentage of dorsally located cells in $\mathrm{DCC}^{-/-}$mice 


\section{LHRH Cells Located in Dorsal Forebrain}
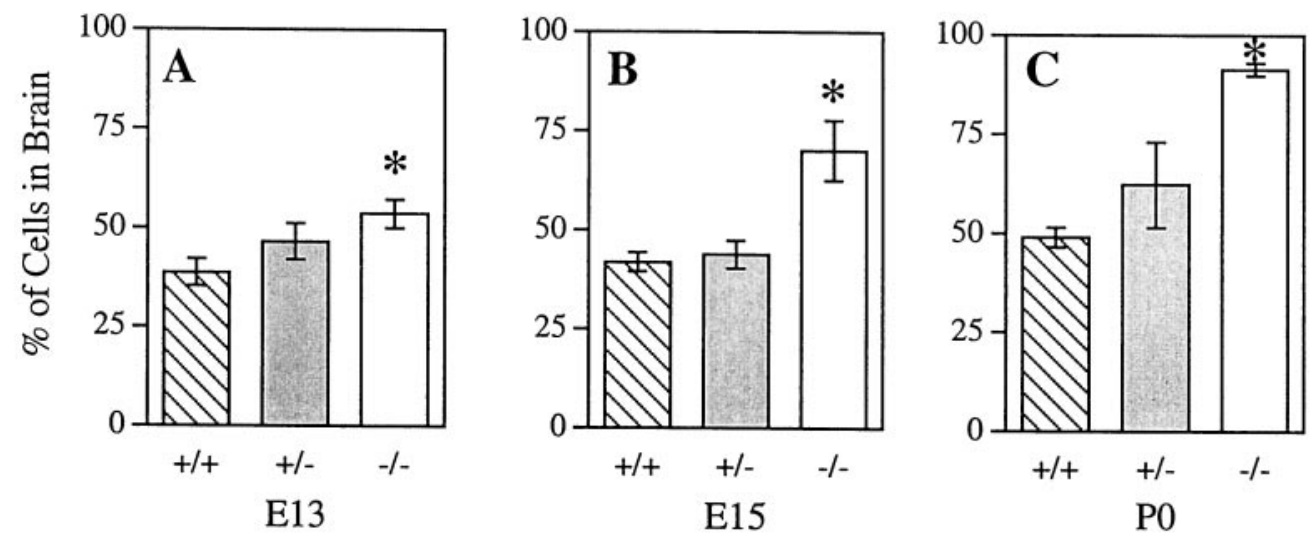

Figure 4. Loss of DCC function altered LHRH neuron location in the embryonic forebrain. The percentage of LHRH neurons located in the dorsal forebrain was significantly greater in DCC homozygous mutant $(-/-)$ embryos compared with wild-type embryos $(+/+)$ at E13, E15, and P0. Although there was a tendency for a greater percentage of cells to be located in the dorsal forebrain of $\mathrm{DCC}^{+/-}$, compared with $\mathrm{DCC}^{+/+}$mice at these ages, the difference did not reach statistical significance $(A-C)$. The percentage of LHRH neurons located in the cortex of $\mathrm{DCC}^{-/-}$mice compared with $\mathrm{DCC}^{+/+}$ mice was also significantly greater at $\mathrm{E} 13$ and E15. There was a tendency for a greater percentage of $\mathrm{LHRH}$ neurons to be located in the cortex of $\mathrm{DCC}^{+/-}$ mice at $\mathrm{E} 13$, and this measure became significantly different from $\mathrm{DCC}^{+/+}$ mice at $\mathrm{E} 15(D, E)$. *Significantly different from $\mathrm{DCC}^{+/+} ; p<0.05$, by post hoc Tukey-Kramer HSD.

was significantly greater than that of both $\mathrm{DCC}^{+/+}$and $\mathrm{DCC}^{+/-}$ mice $(p<0.05$; Tukey-Kramer HSD), and there were no significant differences between $\mathrm{DCC}^{+/+}$and $\mathrm{DCC}^{+/-}$mice (Fig. $4 B, C)$.

The altered migration of LHRH neurons was more striking when numbers of cells located in the cortex were analyzed. There was a significant difference in the percentage of cortical $\mathrm{LHRH}$ cells between genotypes at E13 $\left(F_{(2,9)}=13.19 ; p<0.05\right)$ and E15 $\left(F_{(2,11)}=152.79 ; p<0.05\right)$. At E13 the percentage of cortical LHRH cells in $\mathrm{DCC}^{-1-}$ mice was significantly greater than that of both $\mathrm{DCC}^{+/+}$and $\mathrm{DCC}^{+/-}$mice $(p<0.05$; Tukey-Kramer HSD). There were no significant differences between $\mathrm{DCC}^{+/+}$ and $\mathrm{DCC}^{+/-}$mice (Fig. 4D). At E15 there was a clear effect of gene dosage. All genotypes significantly differed from each other ( $p<0.05$; Tukey-Kramer HSD) with $\mathrm{DCC}^{-1-}$ mice having the greatest percentage followed by $\mathrm{DCC}^{+/-}$mice with an intermediate percentage and $\mathrm{DCC}^{+/+}$mice with the lowest percentage of cortical LHRH cells (Fig. $4 E$ ). At $\mathrm{P} 0$ in all genotypes, there were very few cortical LHRH-labeled cells, and therefore an analysis was not performed.

\section{Trajectories of the caudal branch of the vomeronasal nerve in DCC mutant mice}

To determine the mechanism or mechanisms by which loss of DCC expression could result in mispositioning of LHRH neurons, we performed immunocytochemical analysis of the cVNN using antibodies to peripherin and TAG-1. Although peripherin is expressed in many peripheral axons that use this intermediate filament protein, it is an excellent marker for the VNN (Wray et al., 1994). However, it should be noted that LHRH neurons are not peripherin ${ }^{+}$. In sagittal sections through the rostral forebrain of wild-type littermates of DCC-deficient mice, the cVNN made a characteristic turn ventrally and defasciculated into many small fibers (Fig. $5 A$ ). In a matched section from a wild-type littermate (Fig. 5B), LHRH neurons turned ventrally in an identical pattern to the turning of the $\mathrm{cVNN}$. In contrast, most peripherin ${ }^{+}$axons did not turn ventrally in $\mathrm{DCC}^{-1-}$ mice (Fig. $5 E$ ). Furthermore, LHRH neurons also failed to turn ventrally (Fig. $5 F$ ) in $\mathrm{DCC}^{-/-}$ mice; rather, many continued migrating into the cerebral cortex. Interestingly, in $\mathrm{DCC}^{+/-}$mice, there was a tendency for peripherin $^{+}$axons (Fig. $5 C$ ) to exhibit an intermediate phenotype. For example, the cVNN turned ventrally, but at a reduced angle compared with the characteristic turn of the $c V N N$ seen in wild-type mice. As in wild-type and mutant mice, the positions of LHRH neurons in a matched section of the forebrain of heterozygous DCC mice (Fig. 5D) were nearly identical to the trajectories of the $\mathrm{cVNN}$ (Fig. 5C).

\section{LHRH immunoreactivity at PO}

Reproductive competence is dependent on a source of LHRH delivered to the ME in maturing mammals. DCC mutant mice die shortly after birth; thus, it was not possible to determine whether LHRH neurons or their fibers are detectable in the ME of adult homozygous mutant mice. However, it was of interest to analyze 
Figure 5. LHRH neurons follow the caudal vomeronasal nerve. In sagittal sections through the forebrain, the trajectories of the caudal vomeronasal nerve and positions of LHRH neurons were compared in $\mathrm{DCC}^{+/+}, \mathrm{DCC}^{+/-}$, and $\mathrm{DCC}$ mice at E13. Immunocytochemical analysis with antibodies to peripherin show the typical turn made by the cVNN in the forebrain of wild-type mice $(A$, arrow $)$ and the many defasciculated fibers growing toward the basal forebrain (arrowheads). Most LHRH neurons also turn ventrally in the forebrain of wild-type mice $(B)$. In $\mathrm{DCC}^{+/-}$mice $(C)$, the peripherin ${ }^{+} \mathrm{cVNN}$ also turns toward the basal forebrain, although the number of defasciculated fibers (arrowheads) and the degree of axon turning may be decreased compared with wild-type mice. The positions of LHRH neurons in heterozygous DCC mice $(D)$ parallel the trajectories of the axons in $C$. In homozygous mutant DCC mice, most peripherin ${ }^{+}$axons fail to turn $(E$, arrow $)$, and there are few defasciculated fibers $(E$, arrowhead) growing to the basal forebrain. In DCC $^{-1-}$ mice, LHRH neurons $(F)$ fail to turn ventrally and migrate instead along the medial wall of the cerebral cortex. Dorsal is up, caudal is right. Scale bar, $100 \mu \mathrm{m}$.

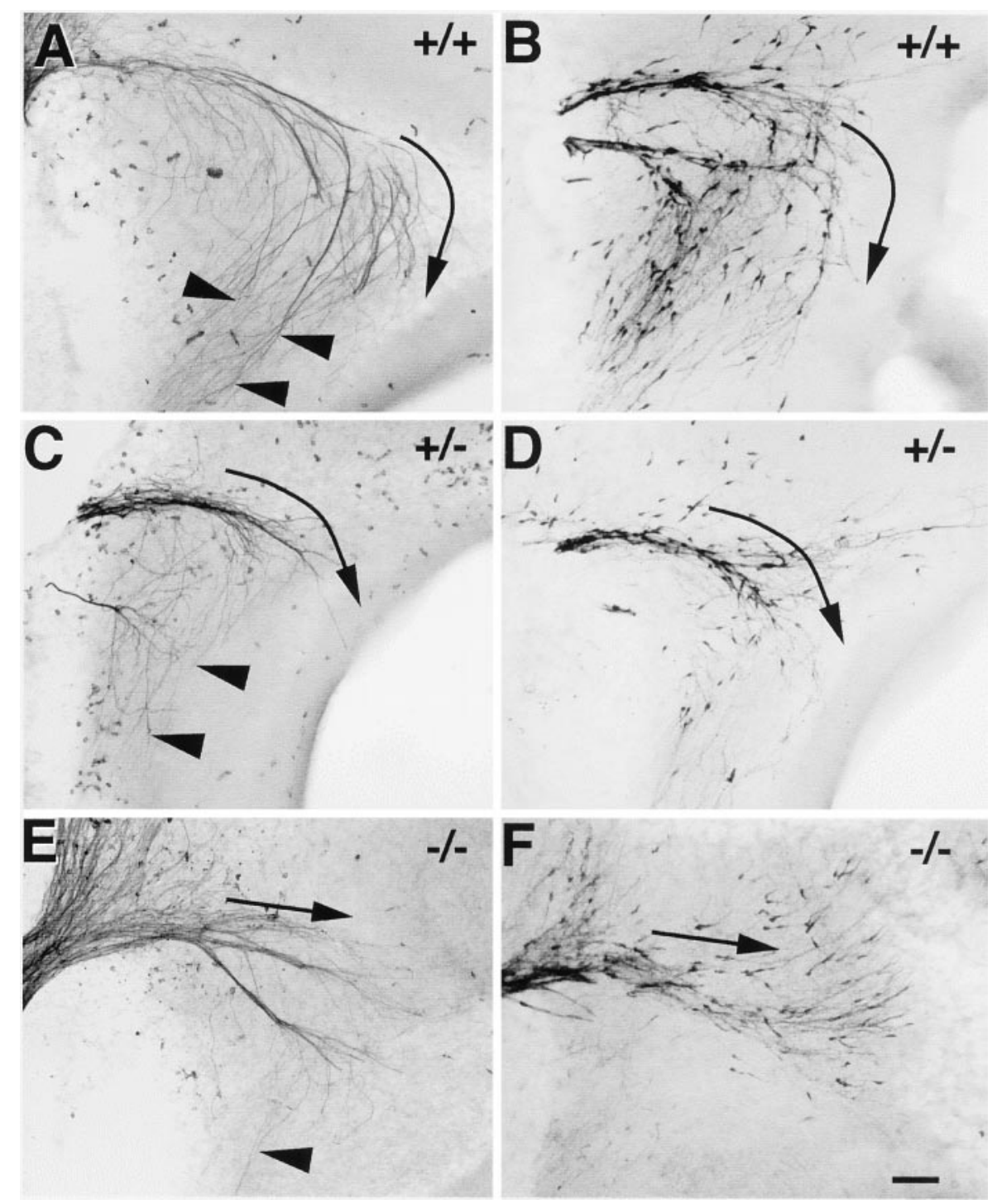

LHRH immunoreactivity in the ventral forebrain of $\mathrm{DCC}^{+/+}$ and $\mathrm{DCC}^{-1-}$ mice at P0. The boundaries used to define cortical, dorsal, and ventral brain locations are shown in Figure $6 \mathrm{~A}$. In wild-type mice many LHRH neurons and fibers were seen throughout the ventral forebrain stretching from the olfactory bulbs to the ME in a clearly rostral to caudal orientation (Fig. $6 B$ ). In contrast, in $\mathrm{DCC}^{-/-}$mice (Fig. $6 C$ ), LHRH cells were more dorsal in location and orientation, and the density of fibers reaching the $\mathrm{ME}$ was notably reduced. As shown above, the number of $\mathrm{LHRH}$ neurons in $\mathrm{DCC}^{-/-}$mice was greatly reduced compared with wild-type mice at $\mathrm{P} 0$, at least partially because of the disappearance (i.e., no longer detectable) of the cells previously noted in the most dorsal cortical locations.

\section{DISCUSSION}

\section{Axonal guidance of LHRH neuron migration}

There are $1200-1500$ LHRH neurons that migrate from the VNO to the ventral forebrain in mice (Wu et al., 1997; Yoshida et al., 1999; Bless et al., 2000a). At E11 and E12, most of these neurons are still in the nasal compartment, but between E13 and E15 most LHRH neurons have migrated across the cribriform plate into the forebrain. In the forebrain LHRH neurons make a ventral turn and migrate farther into the hypothalamus. We have previously shown that LHRH neurons migrate in contact with the vomeronasal nerve (Yoshida et al., 1995). Figure 7 is a schematic representation of the relationship between migrating $\mathrm{LHRH}$ neurons and the vomeronasal nerve. In both rats and mice, the vomeronasal nerve in the nasal compartment ( $\mathrm{nVNN}$ ) emerges from the VNO as several large fascicles, which converge at the junction of the nose and brain. After crossing the cribriform plate, the nVNN splits into two branches. The dorsal branch extends across the medial surface of the OB (obVNN, shown in blue), terminating in the accessory olfactory bulb. The other branch extends caudally and ventrally into the forebrain (cVNN, shown in red). We have previously shown that the $\mathrm{cVNN}$ expresses TAG-1 in rats and mice, whereas the obVNN does not (Yoshida et al., 1999). Furthermore, many neurons that make up the cVNN projection migrate away from the $\mathrm{VNO}$ and take up residence along the $\mathrm{nVNN}$. Here we further demonstrate that the $\mathrm{cVNN}$ in rats specifically expresses the DCC protein, and that many $\mathrm{DCC}^{+}$ cells (shown in red) migrate from the VNO before projecting an axon into the forebrain. The vast majority of LHRH neurons (black cells) prefer to migrate along the cVNN rather than the obVNN, although the molecular basis for this choice is unknown. 


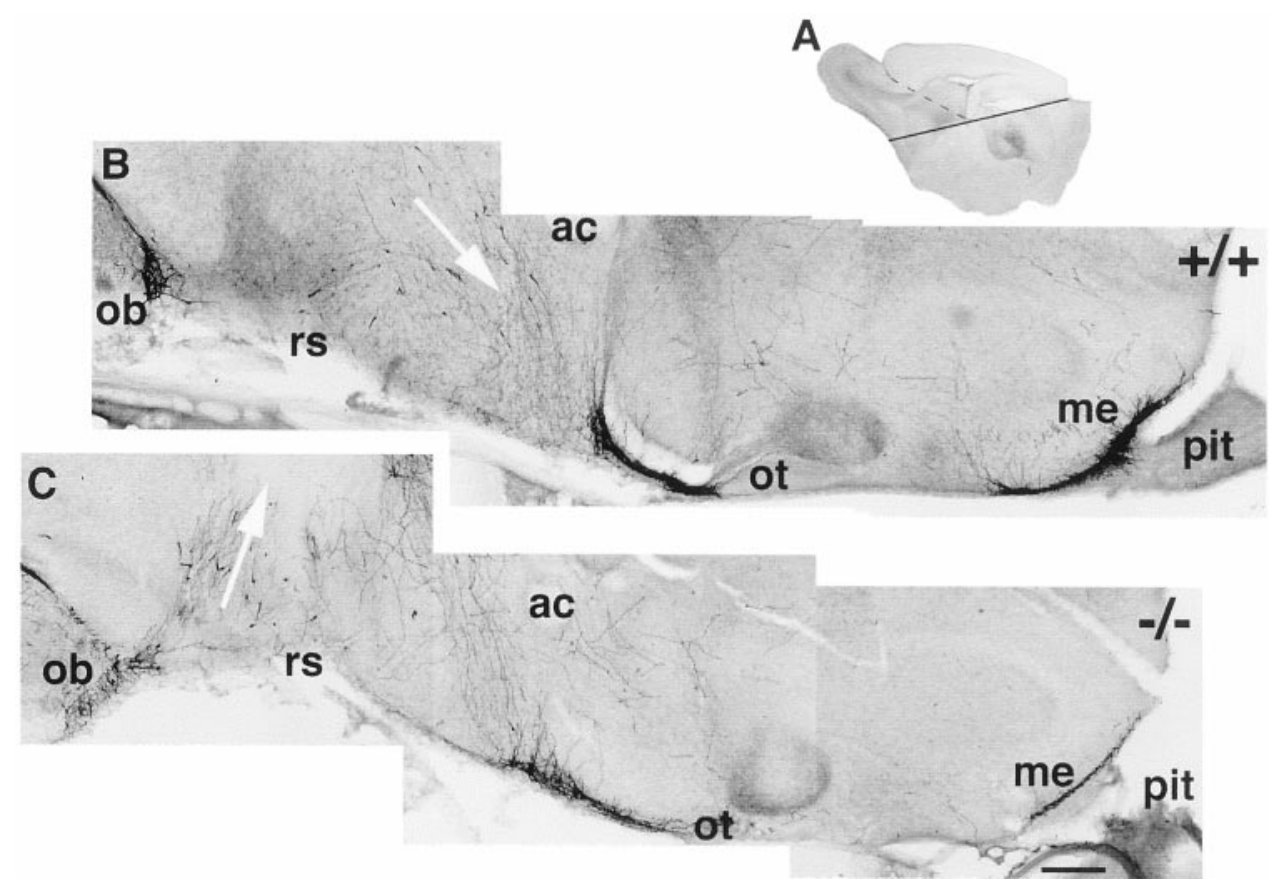

Figure 6. Few LHRH fibers reach the median eminence (me) in the $\mathrm{DCC}^{-/-}$basal forebrain at $\mathrm{P} 0$. In a sagittal section of a $\mathrm{P} 0$ mouse brain $(A)$, a solid line connecting the rhinencephalic sulcus (rs) and the cortical mantle establishes a dorsal ventral boundary. The dashed line connecting the accessory olfactory bulb with the roof of the hypothalamus defines the boundary that was used to designate a more extreme subset labeled as cortex. Immunocytochemistry for LHRH in sagittal sections through the basal forebrain at $\mathrm{P} 0$ was performed in DCC-deficient mice and their wild-type littermates. At $\mathrm{P} 0$, in wildtype mice, many LHRH neurons have migrated deep into the basal forebrain, and many LHRH fibers have reached the ME $(B)$. In contrast, in a matched section through the forebrain of a homozygous mutant littermate $(C)$, LHRH cells are located and oriented more dorsally (compare white arrows), and only a few fibers are detectable at the ME adjacent to the pituitary (pit). The rhinencephalic sulcus that was used to help designate a dorsal boundary in conjunction with the cortical mantle in analyses at E13 and E15 (Fig. 4) continues to indicate an apparent border for LHRH neurons in $\mathrm{DCC}^{-/-}$animals at P0. $o b$, Olfactory bulb; ot, optic tract; $a c$, anterior commissure. Dorsal is $u p$, rostral is left. Scale bar, $200 \mu \mathrm{m}$.

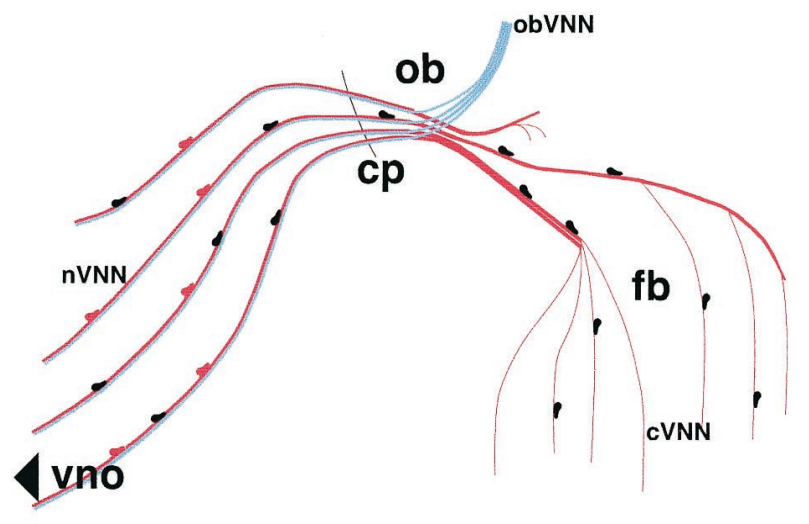

$\mathrm{DCC}+/+$

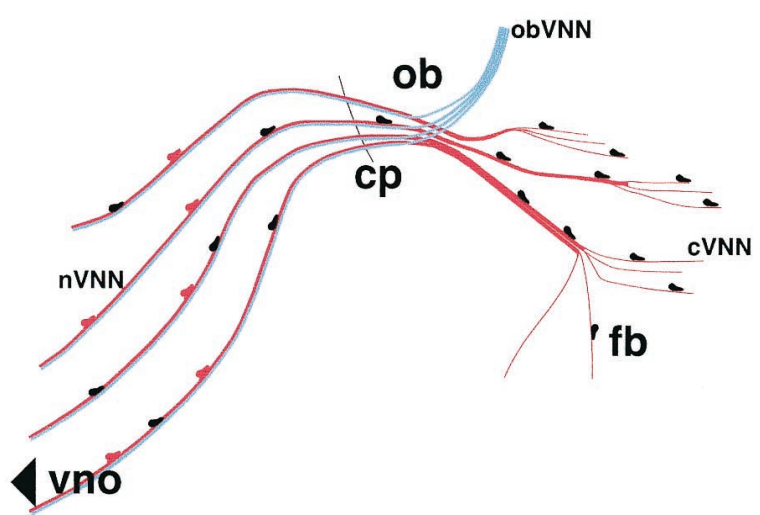

DCC $-/-$

Figure 7. Schematic illustration of axon trajectories and LHRH neuron positions in wild-type and DCC-deficient mice. In DCC ${ }^{+/+}$mice the nasal vomeronasal nerve $(n V N N)$ originates in the VNO and splits after crossing the cribriform plate $(c p)$. One branch grows dorsally to the accessory olfactory bulb $(o b V N N)$, and another branch grows caudally $(c V N N)$ into the ventral forebrain. Most LHRH neurons follow the cVNN to the forebrain. In DCC ${ }^{-1-}$ mice, the nVNN branches normally into the obVNN and the cVNN. However, the majority of axons that make up the cVNN fail to make their characteristic ventral turn in DCC-deficient mice and grow into the medial wall of the cerebral cortex. Many LHRH neurons follow the aberrant trajectories of the cVNN and migrate into the cortex of DCC mutant mice.

\section{Aberrant trajectories of the cVNN in DCC ${ }^{-1-}$ mice}

Although the growth of the obVNN appears normal throughout development, the trajectories of the $\mathrm{cVNN}$ are abnormal in DCC-deficient mice. Rather than turning toward the hypothalamus as it does in control mice, the $\mathrm{CVNN}$ in DCC-deficient mice extends into the medial wall of the cerebral cortex. In $\mathrm{DCC}^{-/-}$ mice, as in $\mathrm{DCC}^{+/+}$mice, LHRH neurons migrate in contact with the cVNN. By following the $\mathrm{cVNN}$ in mutant mice, however, many LHRH neurons migrate into the cortex. These results suggest that DCC plays a negligible role in the initiation of cell migration or axon extension from the VNO, because these appear to take place normally in mutants. Furthermore, branching of the $n V N N$ into the obVNN and cVNN also appears to be DCCindependent. Interestingly, even the pattern of $\mathrm{cVNN}$ branching and defasciculation in the forebrain appears relatively normal in $\mathrm{DCC}^{-/-}$mice. The obvious defect in this system in DCCdeficient mice appears to be that the $\mathrm{cVNN}$ either fails to turn or turns inappropriately. The aberrant trajectories taken by the $\mathrm{cVNN}$ in DCC-deficient mice suggest that in the absence of a DCC-mediated axon turning mechanism, either the axons continue to grow autonomously or are directed by a different set of guidance cues which send cVNN axons dorsally into the cortex. 


\section{Aberrant LHRH neuron migration in $\mathrm{DCC}^{-/-}$mice}

Between E13 and P0, there is a steady increase in the percentage of LHRH neurons that have reached the ventral forebrain in the CD-1 wild-type mice used in this study. At E13 approximately one third of the LHRH cells that have crossed the cribriform plate have already progressed to the ventral forebrain. By P0, approximately half of LHRH cells that have left the nose have migrated to the ventral forebrain. In DCC mutant mice, however, the percentage of LHRH neurons in the ventral forebrain at E13, $\mathrm{E} 15$, and at $\mathrm{P} 0$ is $<10 \%$ of the total population that crossed the cribriform plate. Approximately $20 \%$ of LHRH neurons are located in the cortex of $\mathrm{DCC}^{-/-}$mice at E13 and E15. This is more than fivefold the number of LHRH neurons that migrate into the cortex of wild-type mice at E15. The appearance of the trajectories of the $\mathrm{cVNN}$ and positions of LHRH neurons seen at E13 (Fig. $5 F$ ) would suggest that a much higher percentage of these cells might migrate into the cortex. However, the total number of LHRH neurons in $\mathrm{DCC}^{-1-}$ mice does not change from E13 to E15 and is 25-30\% less than the number of LHRH neurons in wild-type and heterozygous mice at E15. By P0, there are few LHRH neurons remaining in the cortex of DCC-deficient mice, and the total number of LHRH neurons in the brain of $\mathrm{DCC}^{-1-}$ mice is reduced by approximately one-third compared with $\mathrm{DCC}^{+/+}$littermates. Although the cause of the reduced number of detectable LHRH neurons in DCC-deficient mice is unknown, it is possible that these cells either die or produce undetectable amounts of peptide because of their migration into an inappropriate environment.

At P0, the latest time point in development that we could analyze DCC ${ }^{-1-}$ mice, few LHRH cells could be found in their normal locations in the hypothalamus. Interestingly, as was previously shown (Deiner and Sretavan, 1999), some $\mathrm{LHRH}^{+}$fibers reach the $\mathrm{ME}$ in DCC-deficient mice, although their cell bodies remain in more dorsal positions. The fact that any $\mathrm{LHRH}^{+}$axons grow into the ME in DCC-deficient mice from neurons located at much larger distances than in wild-type mice lends support to the idea that a factor attracts $\mathrm{LHRH}^{+}$processes to the ME after the cells have reached their destination (Rogers et al., 1997; Wu et al., 1997). These data further suggest that such a factor is DCCindependent. It is likely that decreased LHRH innervation of the $\mathrm{ME}$ results from the reduced total numbers of $\mathrm{LHRH}$ neurons in the brain of $\mathrm{DCC}^{-/-}$mice at $\mathrm{P} 0$, and the near absence of these neurons in their normal positions in the hypothalamus at this age.

\section{LHRH neuron heterogeneity}

Although the total number of LHRH neurons is relatively small, they are notably heterogeneous based on a number of criteria in development and in adulthood. For example, we previously found select glycoconjugates on subsets of LHRH neurons in development (Tobet et al., 1993; Bless et al., 2000b). We also found the neurotransmitter GABA in a small subset of LHRH neurons early in development (Tobet et al., 1996). GABA in particular may be important for aspects of LHRH neuron migration and development based on several studies in vitro and in vivo (Fueshko et al., 1998; Bless et al., 2000a). The results presented here suggest that DCC is expressed by a subset of LHRH neurons in the nasal compartment. If DCC expression in LHRH neurons plays a specific role in the subset of neurons that express it, then it is likely early in their migration, because DCC expression is downregulated before LHRH neurons cross into the forebrain. This also makes it less likely that DCC expression in LHRH neurons plays a role in determining their final locations in the forebrain.
Interestingly, $75-90 \%$ of LHRH neurons followed the misdirected $\mathrm{cVNN}$, and many of the remaining neurons that turned caudally appeared to follow the remnant of the cVNN that maintained its ventral turn. Therefore, regardless of the heterogeneity of LHRH neurons, the one rule they appear to follow is that the cVNN is an obligatory pathway. This is further suggested by studies in parasagittal slices of embryonic mouse heads in which mechanically altered fiber trajectories directly adjust LHRH neuron migration (Tobet et al., 2001).

We have also presented evidence that heterozygous DCC mice have a mild phenotype. At both E13 and E15, the percentage of LHRH neurons in the dorsal forebrain and percentage of neurons in the cortex of $\mathrm{DCC}^{+/-}$mice is intermediate between wild-type and mutant values. The percentage of neurons in the $\mathrm{DCC}^{+/-}$cortex at E15 is significantly different from wild-type mice. Furthermore, axon trajectories of the $\mathrm{cVNN}$ and the orientation and positions of LHRH neurons in $\mathrm{DCC}^{+/-}$mice at E13 (Fig. 5C,D) appear midway between the axon trajectories and cell positions in either wild-type or mutant mice from the same litter. These results suggest that DCC gene dosage may provide a means of regulating the relative response of a $\mathrm{DCC}^{+}$axon to a netrin- 1 source. Other guidance cues, for example, ephrins and Eph receptors are presumed to function by interactions of complementary concentration gradients. It was recently shown that relative levels of EphA receptors on retinal ganglion cells regulate targeting of their axons to the superior colliculus (Brown et al., 2000). Whether graded expression of DCC on axons functions in guidance of the cVNN remains to be determined.

\section{REFERENCES}

Ackerman SL, Kozak LP, Przyborski SA, Rund LA, Boyer BB, Knowles BB (1997) The mouse rostral cerebellar malformation gene encodes an UNC-5-like protein. Nature 286:838-842.

Bless EP, Westaway WA, Schwarting GA, Tobet SA (2000a) Effects of gamma-aminobutyric acid (A) receptor manipulation on migrating gonadotropin-releasing hormone neurons through the entire migratory route in vivo and in vitro. Endocrinology 141:1254-1262.

Bless EP, Pays L, Schwarting GA, Tobet SA (2000b) Expression of a cell surface glycoconjugate in gonadotropin releasing hormone $(\mathrm{GnRH})$ neurons in mice. Soc Neurosci Abstr 25:1350.

Brown A, Yates PA, Burrola P, Ortuno D, Vaidya A, Jessell TM, Pfaff SL, O'Leary DDM, Lemke G (2000) Topographic mapping from the retina to the midbrain is controlled by relative but not absolute levels of EphA receptor signaling. Cell 102:77-88.

Colamarino SA, Tessier-Lavigne M (1995) The axonal chemoattractant netrin-1 is also a chemorepellent for trochlear motor axons. Cell 81:187-195.

Cooper HM, Armes P, Britto J, Gad J, Wilkes AF (1995) Cloning of the mouse homologue of the deleted in colorectal cancer gene (mDCC) and its expression in the developing mouse embryo. Oncogene 11:2243-2254.

DeCarlos JA, Lopez-Mascaraque L, Valverde F (1995) The telencephalic vesicles are innervated by olfactory placode-derived cells: a possible mechanism to induce neocortical development. Neuroscience 68:1167-1178.

Deiner MS, Sretavan DW (1999) Altered midline axon pathways and ectopic neurons in the developing hypothalamus of netrin-1- and DCCdeficient mice. J Neurosci 19:9900-9912.

Dodd J, Morton SB, Karagogeos D, Yamamoto M, Jessell TM (1988) Spatial regulation of axonal glycoprotein expression on subsets of embryonic spinal neurons. Neuron 1:105-116.

Fazeli A, Dickenson SL, Hermiston ML, Tighe RV, Steen RG, Small CJ, Stoeckli ET, Keino-Masu K, Masu M, Rayburn H, Simons J, Bronson RT, Gordon JI, Tessier-Lavigne M, Weinberg RA (1997) Phenotype of mice lacking functional Deleted in colorectal cancer (Dcc) gene. Nature 386:796-804.

Fueshko SM, Key S, Wray S (1998) GABA inhibits migration of luteinizing hormone-releasing hormone neurons in embryonic olfactory explants. J Neurosci 18:2560-2569.

Garrosa M, Iniguez C, Fernandez JM, Gayoso MJ (1992) Developmental stages of the vomeronasal organ in the rat: a light and electron microscopic study. J Hirnforsch 33:123-132.

Halpern M (1987) The organization and function of the vomeronasal system. Rev Neurosci 10:325-362. 
Hedgecock EM, Culotti JG, Hall DH (1990) The unc-5, unc-6 and unc-40 genes guide circumferential migration of pioneer axons and mesodermal cells on the epidermis in C. elegans. Neuron 2:241-246.

Kennedy TE, Serafini T, de la Torre JR, Tessier-Lavigne M (1994) Netrins are diff usible chemotropic factors for commissural axons in the embryonic spinal cord. Cell 78:425-435.

Keino-Masu K, Masu M, Hinck L, Leonardo ED, Chan SSY, Culotti JG, Tessier-Lavigne M (1996) Deleted in colorectal cancer (DCC) encodes a netrin receptor. Cell 87:175-185.

Leonardo ED, Hinck L, Masu M, Keino-Masu K, Ackerman SL, TessierLavigne (1997) Vertebrate homologues of $C$. elegans UNC-5 are candidate netrin receptors. Nature 386:833-838.

Livesey FJ, Hunt SP (1997) Netrin and netrin receptor expression in the embryonic mammalian nervous system suggests roles in retinal, striatal, nigral, and cerebellar development. Mol Cell Neurosci 8:417-429.

Norgren RB, Brackenbury R (1993) Cell adhesion molecules and the migration of LHRH neurons during development. Dev Biol 160:377-387.

Przyborski SA, Knowles BB, Ackerman SL (1998) Embryonic phenotype of Unc5h3 mutant mice suggests chemorepulsion during the formation of the rostral cerebellar boundary. Development 125:41-50.

Quanbeck C, Sherwood NM, Millar RP, Terasawa E (1997) Two populations of luteinizing hormone-releasing hormone neurons in the forebrain of the rhesus macaque during embryonic development. J Comp Neurol 380:293-309.

Rogers MC, Silverman AJ, Gibson MJ (1997) Gonadotropin-releasing hormone axons target the median eminence: in vitro evidence for diffusible chemoattractive signals from the mediobasal hypothalamus. Endocrinology 138:3956-3966.

Ronnekleiv OK, Resko JA (1990) Ontogeny of gonadotropin-releasing hormone-containing neurons in early fetal development of rhesus macaques. Endocrinology 126:498-511.

Schwanzel-Fukuda M, Pfaff DW (1989) Origin of luteinizing hormonereleasing hormone neurons. Nature 338:161-164.

Serafini T, Kennedy TE, Galko MJ, Mirzayan C, Jessell TM, TessierLavigne M (1994) The netrins define a family of axon outgrowthpromoting proteins homologous to C. elegans UNC-6. Cell 78:409-424.

Shu T, Valentino KM, Seaman C, Cooper HM, Richards LJ (2000) Expression of the netrin-1 receptor, deleted in colorectal cancer (DCC), is largely confined to projecting neurons in the developing forebrain. J Comp Neurol 416:201-212.
Skynner MJ, Slater R, Sim JA, Allen ND, Herbison AE (1999) Promoter transgenics reveal multiple gonadotropin-releasing hormone-Iexpressing cell populations of different embryological origin in mouse brain. J Neurosci 19:5955-5966.

Tobet SA, Crandall JE, Schwarting GA (1993) Relationship of migrating luteinizing hormone-releasing hormone neurons to unique olfactory system glycoconjugates in embryonic rats. Dev Biol 155:471-482.

Tobet SA, Chickering TW, King JC, Stopa EG, Kim K, Kuo-LeBlank V, Schwarting GA (1996) Expression of gamma-aminobutyric acid and gonadotropin-releasing hormone during neuronal migration through the olfactory system. Endocrinology 137:5415-5420.

Tobet SA, Bless EP, Schwarting GA (2001) Developmental aspects of the GnRH neuronal system. Mol Cell Endocrinol, in press.

Wanner I, Baader SL, Brich M, Oberdick J, Schilling K (1997) Subcellular localization of specific mRNAs and their protein products in Purkinje cells by combined fluorescence in situ hybridization and immunocytochemistry. Histochem Cell Biol 108:345-357.

Wray S, Nieburgs A, Elkabes S (1989) Spatiotemporal cell expression of luteinizing hormone-releasing hormone in the prenatal mouse: evidence for an embryonic origin in the olfactory placode. Dev Brain Res 46:309-318.

Wray S, Key S, Qualls R, Fueshko SM (1994) A subset of peripherin positive olfactory axons delineates the luteinizing hormone releasing hormone neuronal migratory pathway in developing mouse. Dev Biol 166:349-354.

Wu TJ, Gibson MJ, Rogers MC, Silverman AJ (1997) New observations on the development of the gonadotropin-releasing hormone system in the mouse. J Neurobiol 33:983-998.

Yamamoto M, Boyer AM, Crandall JE, Edwards M, Tanaka H (1986) Distribution of stage-specific neurite-associated proteins in the developing murine nervous system recognized by a monoclonal antibody. J Neurosci 6:3576-3594.

Yoshida K, Tobet SA, Crandall JE, Jimenez TP, Schwarting GA (1995) The migration of luteinizing hormone-releasing hormone neurons in the developing rat is associated with a transient, caudal projection of the vomeronasal nerve. J Neurosci 15:7769-7777.

Yoshida K, Rutishauser U, Crandall JE, Schwarting GA (1999) Polysialic acid facilitates migration of luteinizing hormone-releasing hormone neurons on vomeronasal axons. J Neurosci 19:794-801. 